\title{
Calcium Uptake and Whole-plant Water Use Influence Pod Calcium Concentration in Snap Bean Plants
}

\author{
Kirk W. Pomper ${ }^{1}$ and Michael A. Grusak \\ U.S. Department of Agriculture, Agricultural Research Service, Children's Nutrition Research Center, \\ Department of Pediatrics, Baylor College of Medicine, 1100 Bates Street, Houston, TX 77030
}

\begin{abstract}
ADDITIONAL INDEX WORDS. Phaseolus vulgaris, nutrition, minerals, mineral requirements, green beans, vegetables, human nutrition, bioavailability, health, postharvest

ABSTRACT. Understanding the mechanisms that regulate xylem transport of calcium (Ca) to snap bean (Phaseolus vulgaris $\mathrm{L}$.) pods could allow approaches to increase pod Ca concentration and enhance the nutritional value of edible pods. Using the snap bean cultivars Hystyle and Labrador, which exhibit high and low pod Ca levels, respectively, we wished to determine whether there were differences between the two cultivars in stem xylem-sap Ca concentration and whether any differences in sap Ca concentration were related to differences in whole-plant water uptake or Ca import between the cultivars. Well-watered greenhouse-grown plants were placed in a growth chamber at a constant light intensity for an equilibration period. Pot weight loss was measured to determine whole-plant water use and stem xylem exudate was subsequently collected from the severed base of the shoot at flowering and at two stages of pod development. 'Hystyle' displayed an exudate Ca concentration that was $50 \%$ higher than 'Labrador' during pod development. 'Labrador' showed $35 \%$ greater total water transport through the stem than 'Hystyle'. 'Labrador' plants also showed a significantly larger leaf area than 'Hystyle' plants. Additional plants were used to determine total, long-term Ca influx. No difference was observed between cultivars in total Ca influx into the aerial portion of the plant. With whole-shoot Ca influx being equivalent and pod transpiration rate identical in the two cultivars, our results suggest that the higher whole-plant water uptake in 'Labrador' led to a dilution of Ca concentration in the xylem stream and thus less total Ca was transported to developing pods, relative to that in 'Hystyle'. Increased transpiration efficiency, enhanced root uptake of $\mathrm{Ca}$, or reduced $\mathrm{Ca}$ sequestration in the xylem pathway of the stem could lead to an enhancement in pod Ca concentration in future cultivars of snap bean.
\end{abstract}

Calcium is an essential element in human nutrition due to its structural role in bone development and in regulating cellular metabolism (Linder, 1991). Guidelines suggest that humans should consume $\approx 1000$ to $1300 \mathrm{mg}$ of Ca per day, the equivalent of $1 \mathrm{~L}$ of milk (Institute of Medicine, 1997). Adolescents should consume at least $1300 \mathrm{mg}$ of Ca per day in an effort to reduce the risk of osteoporosis later in life (Johnston et al., 1992). Adequate Ca nutrition may also decrease the risk of colon cancer (Bruce, 1987). Although dairy products provide a majority of the Ca needs of humans, milk intake in the United States has declined in recent years. Dairy products represent $55 \%$ and $46 \%$ of the total $\mathrm{Ca}$ intake in adolescent and young adult females, respectively (Penninton and Young, 1991).

Snap bean pods are high in bioavailable $\mathrm{Ca}$, being low in compounds that can inhibit absorption (e.g., phytate, oxalate) upon digestion (Heaney et al., 1988). When compared to other fruits and vegetables, snap beans display a high Ca concentration ( $\approx 5 \mathrm{mg} \cdot \mathrm{g}^{-1}$ dry weight) (Quintana et al., 1996). Snap beans are well liked by children, as well as adults, thus making this food an ideal candidate for nutritional improvement (Pao et al., 1982). Understanding mechanisms that regulate partitioning of $\mathrm{Ca}$

Received for publication 9 Jan. 2004. Accepted for publication 20 May 2004. This project has been funded in part with federal funds from the U.S. Dept. of Agriculture, Agricultural Research Service, under Cooperative Agreement No. 58-6250-6-001. The contents of this publication do not necessarily reflect the views or policies of the U.S. Dept. of Agriculture, nor does mention of trade names, commercial products, or organizations imply endorsement by the U.S. Government.

${ }^{1}$ To whom reprint requests should be addressed. Current address: Principal investigator of horticulture and curator of the USDA National Clonal Germplasm Repository for Asimina spp., Atwood Research Facility, Kentucky State Univ., Frankfort, KY 40601-2355 within the snap bean plant could allow for enhancement in the $\mathrm{Ca}$ concentration of the edible pods by breeding, biotechnological, or production approaches.

Within the snap bean plant, regulation of Ca partitioning to the pods is incompletely understood. Transpiration, as well as growth induced water uptake by developing plant organs, appears to drive the transport of $\mathrm{Ca}$ in the xylem pathway to vegetative tissues of the snap bean plant (Bell and Biddulph, 1963; Biddulph et al., 1959, 1961; Mix and Marschner, 1976; Nonami and Boyer, 1987). When atmospheric relative humidity is increased by covering the whole plant (leaves and pods) in a plastic enclosure, pod $\mathrm{Ca}$ concentration is lowered, indicating that whole-plant and/or pod transpiration are important determinants of Ca partitioning to pods (Mix and Marschner, 1976).

The inability to remobilize $\mathrm{Ca}$ from terminal organs, such as snap bean leaves, requires continual root uptake and xylem transport of Ca for continued delivery to mature and developing organs (Hose et al., 2001; Raven, 1977; White, 2001). Increasing soil Ca levels with gypsum does not result in an increase in Ca concentration of snap bean pods (Miglioranza et al., 1997), suggesting that net root $\mathrm{Ca}$ influx is saturated at low soil $\mathrm{Ca}$ levels and may be regulated by the plant. Differential Ca uptake by snap bean roots (Grusak et al., 1996a), as well as sequestration along the xylem pathway in cells as Ca-oxalate crystals (ZindlerFrank, 1995), may represent limiting steps in the transport of Ca to the pods.

Quintana et al. (1996) evaluated 64 snap bean breeding lines and cultivars in two environments and found a 2 -fold range in $\mathrm{Ca}$ concentration in pods; this variation had a significant genetic basis. Two of the commercial cultivars from this evaluation, 'Hystyle', which displays a high pod Ca concentration, and 'Labrador', 
which exhibits a low pod $\mathrm{Ca}$ concentration, have been further examined in an effort to identify a physiological basis for the pod $\mathrm{Ca}$ differences. Both cultivars have similar net-influx rates of $\mathrm{Ca}$ into the aerial portion of the plant (Grusak et al., 1996a). Grusak and Pomper (1998) found that although developing pods of 'Hystyle' have twice the stomatal density of 'Labrador', pod transpiration rates measured on intact pods were similar for both cultivars under equivalent environmental conditions. Interestingly, when developing pods of 'Hystyle' and 'Labrador' were placed under identical water-saturated environments, differences in pod Ca concentration were maintained between the two cultivars, suggesting that xylem sap delivered to 'Hystyle' had a higher concentration of Ca (Grusak and Pomper, 1998).

Based on these physiological examinations demonstrating similar root Ca uptake and pod transpiration, it was hypothesized that differences in Ca concentration of the xylem sap delivered to pods of 'Hystyle' and 'Labrador' could explain the cultivar differences in pod $\mathrm{Ca}$ concentration (e.g., higher xylem-sap $\mathrm{Ca}$ concentration would lead to a higher pod $\mathrm{Ca}$ concentration in 'Hystyle'). Thus, the objectives of this study were to 1) determine whether the Ca concentration of 'Hystyle' xylem sap was higher than that of 'Labrador', and 2) determine whether any observed differences in $\mathrm{Ca}$ concentration of stem xylem sap were related to differences in water or $\mathrm{Ca}$ import rates into the aerial portion of the snap bean cultivars.

\section{Materials and Methods}

Plant material. Greenhouse-grown snap bean plants of the cultivars Labrador and Hystyle were grown during the winter and spring months in 1.5-L plastic pots in Metro Mix (Scotts-Sierra Horticultural Products Co., Marysville, Ohio). The greenhouse was maintained at $25^{\circ} \mathrm{C}$ day $/ 18^{\circ} \mathrm{C}$ night and metal halide lamps provided supplemental irradiance [minimum photosynthetic photon flux $(P P F)$ of $200 \mu \mathrm{mol} \cdot \mathrm{m}^{-2} \cdot \mathrm{s}^{-1}$ at the top of the canopy] with a 12-h photoperiod (lights on at $0800 \mathrm{HR}$ ). An automatic watering system delivered $200 \mathrm{~mL}$ of a nutrient solution to each pot twice daily. This volume of solution was sufficient to saturate the soil, with excess solution allowed to drain from the pot. Plants were watered daily and fertilized with $3 \mathrm{~mm} \mathrm{KNO}_{3}, 0.275 \mathrm{mM} \mathrm{CaCl}_{2}$, $0.25 \mathrm{~mm} \mathrm{MgSO}_{4}$, and $0.25 \mathrm{~mm} \mathrm{KH}_{2} \mathrm{PO}_{4}$. Micronutrient minerals were not added daily as these were presumed to be adequately provided from the soil mix for the short duration of the experiments (no signs of micronutrient deficiency were observed). Soil $\mathrm{pH}$ varied from $\mathrm{pH} 5.0$ (initial) to $\mathrm{pH} 6.0$ (final).

Xylem sap Ca Concentration. Using a completely randomized design, a greenhouse experiment was conducted to determine the Ca concentration of xylem exudate collected from the cultivars Hystyle and Labrador at three stages of development. There were four replicate plants in each treatment combination for a total of 24 plants $(2 \times 3 \times 4=24)$. Plants of each cultivar were grown at the same time and were randomly assigned positions on benches in the greenhouse. Pots were spaced $\approx 0.4 \mathrm{~m}$ apart on the benches (6 plants $/ \mathrm{m}^{2}$ ). Stem exudate was collected from four bean plants each at 32, 42, and $50 \mathrm{~d}$ after planting (DAP), which under our greenhouse growth conditions corresponded to the beginning of the developmental stages of R6 (flowering), R7 (pod growth), and R8 (pod filling) respectively (Hall, 1991) for each cultivar. Exudate was collected from plants in the greenhouse after plants were watered on their usual schedule with nutrient solution. Plants were severed with a razor blade at $\approx 5 \mathrm{~cm}$ above the soil and a short length of plastic tubing [Nalgene tubing, $4.0 \mathrm{~mm}$ (5/32 inch) i.d.; Nalge Co., Rochester, N.Y.) was placed onto the cut stem stub protruding from the pot. Consecutive $100-\mu \mathrm{L}$ aliquots of stem exudate were collected from the plastic tube and saved for $\mathrm{Ca}$ analysis using atomic absorption spectrophotometry (AAS) as described by Grusak et al. (1996b). Aliquots were collected from plants for at least $50 \mathrm{~min}$. To determine $\mathrm{Ca}$ concentration in xylem exudate collected at night, exudate was sampled $\approx 3 \mathrm{~h}$ after darkness from four additional plants of each cultivar at 42 DAP and Ca concentration measured.

Whole-Plant WATER LOSS AND XYLEM SAP CA CONCENTRATION. A separate greenhouse experiment was conducted to examine whole plant water loss and Ca concentration of xylem exudate collected from the cultivars Hystyle and Labrador at 32, 42, and 50 DAP. A completely randomized design was used with eight replicate plants in each treatment combination for a total of 48 plants $(2 \times 3 \times 8=48)$. Plants of each cultivar were grown at the same time and were randomly assigned positions on benches in the greenhouse and were again spaced $\approx 0.4 \mathrm{~m}$ apart on the benches $(6$ plants $/ \mathrm{m}^{2}$ ). Plants were removed from the greenhouse and placed in a growth chamber (model PG2V; Controlled Environments Ltd., Winnipeg, Manitoba, Canada). The environmental conditions in the chamber were $25 \pm 0.5{ }^{\circ} \mathrm{C}$, with a relative humidity of $50 \% \pm 5 \%$ and a constant $P P F$ of $550 \mu \mathrm{mol} \cdot \mathrm{m}^{-2} \cdot \mathrm{s}^{-1}$ at the top of the canopy. The pots then were watered with deionized water and covered in plastic bags (including the soil surface). After a 2-h equilibration period in the growth chamber, the plants were weighed, and weighed again after an additional $3 \mathrm{~h}$. After the final weighing, stem xylem exudate was collected from plants and assayed for $\mathrm{Ca}$ concentration as described above. All leaves were removed from each plant and leaf area was determined as described by Grusak (1994), except that leaf images were photocopied, cut from the photocopier paper, weighed, and the leaf area calculated.

Plant growth and whole-shoot Ca uptake. Additional plants were grown as described above, in the whole-plant water loss and xylem sap Ca concentration experiment, to determine total, cumulative Ca uptake into the aerial portions of the plant. Pods, stems, and leaves were collected from plants at 32, 42, and 50 DAP. A completely randomized design was used with seven replicate plants in each treatment combination for a total of 42 plants $(2 \times 3 \times 7=42)$. The collected plant parts were dried at 70 ${ }^{\circ} \mathrm{C}$ to a constant weight, ground to a fine powder with a coffee mill, and duplicate 0.5 -g subsamples were wet digested as described in Grusak (1994). Calcium concentrations were determined using AAS; subsample averages were used to calculate total Ca content per tissue fraction for each plant.

Statisticalanalysis. Exudate Ca concentration, whole-plant water-use, and total $\mathrm{Ca}$ content, plant dry weight, and leaf area were subjected to an analysis of variance (ANOVA) or general linear model of analysis of variance (GLM-ANOVA) using the statistical software CoStat (CoHort Software, Monterey, Calif.). Statistical significance of differences between mean values was determined using the Student $t$ test.

\section{Results}

Xylem sap Ca concentration. Large quantities of exudate were easily obtained from severed snap bean stems. Initially, consecutive $100-\mu \mathrm{L}$ aliquots of exudate were collected from plants of each cultivar at 42 DAP in the greenhouse in mid-afternoon under sunny conditions. For both cultivars, $\approx 600 \mu \mathrm{L}$ of exudate was collected by the end of $1 \mathrm{~h} ; \approx 2$ to $3 \mathrm{~min}$ was required to collect the first $100 \mu \mathrm{L}$-aliquot (Fig. 1). The first $100-\mu \mathrm{L}$ aliquot 


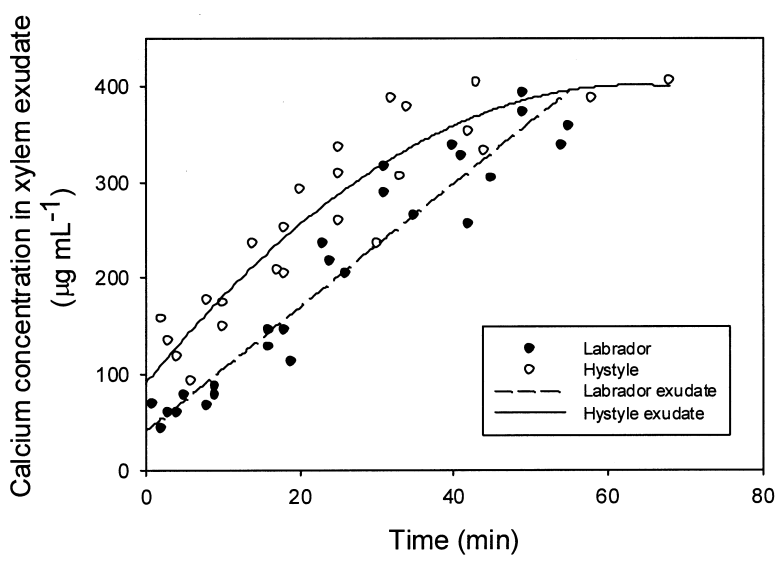

Fig. 1. Calcium concentration in consecutive $100-\mu \mathrm{L}$ aliquots of xylem exudate collected from decapitated snap bean plants at $42 \mathrm{~d}$ after planting in the greenhouse in mid-afternoon under sunny conditions for 'Hystyle' $\left(\mathrm{y}=-0.08 \mathrm{x}^{2}+9.78 \mathrm{x}+\right.$ 90.93; $R^{2}=0.86$; open symbol) and 'Labrador' (y=6.44x $+40.94 ; R^{2}=0.92$; closed symbol). Data collected from four plants of each cultivar are plotted.

collected from each plant displayed the lowest Ca concentration. The sixth $100-\mu \mathrm{L}$ aliquot of exudate was 5-fold higher in $\mathrm{Ca}$ concentration than the first $100-\mu \mathrm{L}$ aliquot. Flow rates $\left(\mu \mathrm{L} \cdot \mathrm{h}^{-1}\right)$ of stem exudate were similar for the two cultivars over the course of the 1-h collection period (data not shown).

The first $100 \mu \mathrm{l}$ of stem exudate was arbitrarily chosen to best represent the xylem-sap concentration in the plant and this quantity was collected from plants in the greenhouse in midafternoon from each cultivar at flowering (32 DAP) and at two stages of pod development (42 and 50 DAP). 'Hystyle' plants displayed a higher exudate Ca concentration than 'Labrador' throughout flowering and pod development (Table 1). The Ca concentration of the first $100 \mu \mathrm{L}$ of stem exudate of 'Hystyle' was $20 \%$ higher than 'Labrador' at flowering (32 DAP), and was 30\% higher than 'Labrador' at 42 and 50 DAP (Table 1). There was a developmental decline in exudate Ca concentration of $37 \%$ in 'Hystyle' and 42\% in 'Labrador' from flowering (32 DAP) until mature green pods were present (50 DAP).

To determine whether plant transpiration influenced xylemsap Ca concentration, stem exudate was collected from plants in darkness, $3 \mathrm{~h}$ after sunset. No difference in Ca concentration was observed between the two cultivars for exudate collected in darkness at 42 DAP (Table 1). However, the Ca concentration was 3.7-fold higher in 'Hystyle' and 5-fold higher in 'Labrador' in exudate collected in darkness, relative to exudate collected from plants of each cultivar in the afternoon.

WHOLE-PLANT WATER LOSS AND XYLEM SAP CA CONCENTRATION. To determine if there was a difference in whole-plant water-use between 'Hystyle' and 'Labrador', plants of both cultivars were placed in a growth chamber under constant environmental conditions to compare transpiration rates. At all stages of development, 'Labrador' displayed about a 35\% higher water-use rate, or flow rate through the stem, than 'Hystyle' (Table 2). Water-use by each individual cultivar was similar at all three stages of plant development. Both cultivar and developmental main effects significantly affected leaf area; there was not a significant interaction between the main effects. 'Labrador' plants had a significantly larger leaf area $\left(2398 \mathrm{~cm}^{2}\right)$ than 'Hystyle' $\left(2037 \mathrm{~cm}^{2}\right)$. Leaf area was significantly greater in plants at $32 \mathrm{DAP}$ compared to plants at 42 and 50 DAP; leaf areas were 1975, 2447, and $2370 \mathrm{~cm}^{2}$ at 32,42 , and 50 DAP, respectively. The average leaf area for 'Labrador' and 'Hystyle' plants at each developmental stage can be found in Table 3.
Table 1. Calcium concentration of the first aliquot $(100 \mu \mathrm{L})$ of exudate collected in midafternoon in the greenhouse from the severed stem of 'Hystyle' and 'Labrador' snap bean plants. ${ }^{2}$

\begin{tabular}{lcc}
\hline & \multicolumn{2}{c}{ Calcium $\left(\mu \mathrm{g} \cdot \mathrm{mL}^{-1}\right)$} \\
\cline { 2 - 3 } DAP & Hystyle & Labrador \\
\hline 32 & $81.4 \pm 1.6^{*}$ & $67.4 \pm 3.9$ \\
42 day & $56.0 \pm 2.9^{*}$ & $43.9 \pm 2.8$ \\
42 night $^{\mathrm{y}}$ & $204.7 \pm 9.2^{\mathrm{Ns}}$ & $218.9 \pm 23.9$ \\
50 & $51.2 \pm 4.4^{*}$ & $38.9 \pm 4.3$ \\
\hline
\end{tabular}

2DAP $=$ days after planting, $n=4$ for each cultivar at each developmental stage. "Indicates that the means are significantly different using a $t$ test with $P<0.05$; NS $=$ nonsignificant.

yAliquot of exudate for $\mathrm{Ca}$ analysis collected from plants during the night instead of midafternoon.

As in the initial greenhouse study, the first $100 \mu \mathrm{L}$ of stem exudate collected from 'Hystyle' plants in the growth chamber displayed a higher Ca concentration than 'Labrador' throughout flowering and pod development (Table 2). Specifically, 'Hystyle' showed an exudate Ca concentration that was $47 \%$ higher at flowering (32 DAP), and 59\% higher midway through pod development (42 DAP) and 27\% higher at harvest (50 DAP) than exudate collected from 'Labrador' (Table 2). During plant development, there was a decline in exudate $\mathrm{Ca}$ concentration of $34 \%$ in Hystyle and 24\% in 'Labrador' from flowering (32 DAP) until mature green pods were present (50 DAP).

Plant growth and long-term Whole-shoot uptake of Ca. Plant growth, as determined by dry weight (DW) measurements of the three plant organs (leaves, stems and pods) at the three time points, was similar for the two cultivars (Table 3 ). The only significant differences were that the total mean DW of 'Labrador' plants $(14.6 \mathrm{~g})$ was significantly larger than that of 'Hystyle' (12.3 g DW) at 42 DAP, and that the mean stem DW was significantly larger at all three time periods in 'Labrador' as compared to 'Hystyle' (32, 42, and 50 DAP). Almost all the weight gain from 42 to 50 DAP was attributable to pod growth in plants of both cultivars.

No significant differences in total whole-shoot $\mathrm{Ca}$ content were seen between cultivars at flowering (32 DAP) or during pod development (42 and 50 DAP) (Table 4). The only significant difference between 'Hystyle' and 'Labrador' in Ca content of the leaves, stems, and pods or flowers, was in significantly larger amounts of $\mathrm{Ca}$ in pods of 'Hystyle' at 42 and $50 \mathrm{DAP}$ than 'Labrador' (Table 4). About 74\% of the total Ca transported in the aerial portion of 50 DAP plants of both cultivars was accumulated in the leaves. By 50 DAP, 'Hystyle' had partitioned $45.2 \mathrm{mg}$ and 'Labrador' $31.1 \mathrm{mg}$ of $\mathrm{Ca}$ to the pods.

The Ca concentration of pods, on a DW basis, was significantly higher at 42 DAP in 'Hystyle' as compared to 'Labrador', being (mean \pm SE) $11.4 \pm 0.5$ and $7.6 \pm 0.7 \mathrm{mg} \cdot \mathrm{g}^{-1} \mathrm{DW}$, respectively. Pods of 'Hystyle'at 50 DAP also displayed a significantly higher Ca concentration at $8.3 \pm 0.8 \mathrm{mg} \cdot \mathrm{g}^{-1} \mathrm{DW}$ as compared to 'Labrador' pods at $5.8 \pm 1.2 \mathrm{mg} \cdot \mathrm{g}^{-1} \mathrm{DW}$. In a separate experiment, 'Hystyle' and 'Labrador' plants grown using one-third the rate of nutrient supply also did not display a significant difference in total wholeshoot $\mathrm{Ca}$ content between the two cultivars at 50 DAP (Student $t$ test level of significance of $0.05, \mathrm{n}=16$ ). However, pods of 'Hystyle' still showed a significantly higher Ca concentration at $10.5 \pm 0.5 \mathrm{mg} \cdot \mathrm{g}^{-1} \mathrm{DW}$ compared to 'Labrador' pods at $7.8 \pm 0.2$ $\mathrm{mg} \cdot \mathrm{g}^{-1} \mathrm{DW}$ (data not shown). 
Table 2. Whole-plant water use measured gravimetrically over a 3-h period in a growth chamber under constant environmental conditions and calcium concentration of exudate (first $100 \mu \mathrm{L}$ ) collected from the severed stem of 'Hystyle' and 'Labrador' snap bean plants. ${ }^{\mathrm{T}}$

\begin{tabular}{|c|c|c|c|c|c|c|}
\hline \multirow[b]{2}{*}{ DAP } & \multicolumn{2}{|c|}{$\begin{array}{c}\text { Whole-plant } \\
\text { water use }\left(\mathrm{g} \cdot \mathrm{h}^{-1}\right)\end{array}$} & \multicolumn{2}{|c|}{$\begin{array}{c}\text { Exudate Ca } \\
\text { concn }\left(\mu \mathrm{g} \cdot \mathrm{mL}^{-1}\right)\end{array}$} & \multicolumn{2}{|c|}{$\begin{array}{l}\text { Leaf area } \\
\left(\mathrm{cm}^{2}\right)\end{array}$} \\
\hline & Hystyle & Labrador & Hystyle & Labrador & Hystyle & Labrador \\
\hline 32 & $34.3 \pm 2.0^{*}$ & $45.8 \pm 2.3$ & $56.3 \pm 4.7^{*}$ & $38.4 \pm 2.5$ & $1821 \pm 77^{*}$ & $2118 \pm 86$ \\
\hline 42 & $37.2 \pm 3.6^{*}$ & $49.1 \pm 4.4$ & $49.4 \pm 5.2^{*}$ & $31.0 \pm 2.2$ & $2185 \pm 117^{*}$ & $2679 \pm 166$ \\
\hline 50 & $34.7 \pm 1.7^{*}$ & $47.9 \pm 4.3$ & $37.1 \pm 6.0^{*}$ & $29.0 \pm 2.8$ & $2199 \pm 121^{*}$ & $2538 \pm 153$ \\
\hline
\end{tabular}

${ }^{2} \mathrm{DAP}=$ days after planting, $\mathrm{n}=8$; *indicates that the means are significantly different between 'Hystyle' and 'Labrador' plant using a $t$ test with $P<0.05$.

Table 3. Total dry weights of the aerial portions of 'Hystyle' and 'Labrador' snap bean plants. ${ }^{\mathrm{z}}$

\begin{tabular}{llcr}
\hline \multirow{2}{*}{ DAP } & Aerial parts & \multicolumn{2}{c}{ Dry wt $(\mathrm{g})$} \\
\cline { 3 - 4 } 32 & Leaves & $4.62 \pm 0.34^{\mathrm{NS}}$ & $5.25 \pm 0.19$ \\
& Stem & $2.05 \pm 0.15^{*}$ & $2.72 \pm 0.09$ \\
& Flowers & $0.20 \pm 0.01^{\mathrm{NS}}$ & $0.25 \pm 0.01$ \\
& Total & $6.87 \pm 0.49^{*}$ & $8.23 \pm 0.27$ \\
42 & Leaves & $7.38 \pm 0.59^{\mathrm{NS}}$ & $8.27 \pm 0.50$ \\
& Stem & $3.43 \pm 0.28^{*}$ & $4.65 \pm 0.31$ \\
& Pods & $1.49 \pm 0.19^{\mathrm{NS}}$ & $1.75 \pm 0.27$ \\
& Total & $12.30 \pm 0.84^{*}$ & $14.67 \pm 0.82$ \\
50 & Leaves & $6.29 \pm 0.78^{\mathrm{NS}}$ & $6.03 \pm 0.77$ \\
& Stem & $3.43 \pm 0.28^{*}$ & $4.26 \pm 0.31$ \\
& Pods & $5.72 \pm 0.88^{\mathrm{NS}}$ & $5.78 \pm 0.66$ \\
& Total & $15.55 \pm 1.89^{\mathrm{NS}}$ & $16.08 \pm 1.57$ \\
\hline
\end{tabular}

${ }^{2} \mathrm{DAP}=$ days after planting, $\mathrm{n}=7$ at both 32 and 42 DAP and $n=6$ at 50 DAP for each cultivar.

*Indicates that the means are significantly different between 'Hystyle' and 'Labrador' plant using a $t$ test with $P<0.05$; NS $=$ nonsignificant.

\section{Discussion}

Xylem sap Collection and Ca Concentration. Using our collection technique, large quantities of xylem exudate were obtained from the severed stem of the snap bean plants. As with any method that is used to sample and measure the components of the plant xylem-sap, it is difficult to determine which aliquot best represents the in vivo composition of the sap. Although the first aliquot of exudate may have contained contamination from damaged cells of the cut stem surface, this aliquot contained the lowest concentration of $\mathrm{Ca}$, and thus contamination seemed minimal. Using a similar method, Ehret and Ho (1986) reported a Ca concentration of $\approx 300 \mu \mathrm{g} \cdot \mathrm{mL}^{-1}$ in stem exudate from tomato (Lycopersicon esculentum Mill.) in a combined sample collected over $6 \mathrm{~h}$, which is similar to the Ca concentration we found in aliquots of exudate from stems of snap bean after $1 \mathrm{~h}$. Since the goal of this study was to determine whether there was a relative difference in $\mathrm{Ca}$ concentration in the xylem-sap delivered to the pod of each cultivar, we chose the first $100-\mu \mathrm{L}$ aliquot of exudate as the best representation of the in vivo situation, and used this in all comparisons. However, comparisons of either the first or later matched aliquots demonstrated that the xylem-sap Ca concentration of 'Hystyle' was higher than that of 'Labrador' at all developmental stages examined.

First aliquots of xylem exudate collected from plants of each cultivar in the greenhouse had a higher $\mathrm{Ca}$ concentration than from those collected from plants in the growth chamber (Tables 1 and 2). This may be due to higher whole-plant transpiration rates in plants in the growth chamber than in the greenhouse.
Table 4. Total amounts of calcium transported into the aerial portion of 'Hystyle' and 'Labrador' snap bean plants. ${ }^{\text {' }}$

\begin{tabular}{|c|c|c|c|}
\hline \multirow[b]{2}{*}{ DAP } & \multirow[b]{2}{*}{ Aerial parts } & \multicolumn{2}{|c|}{ Total Ca (mg) } \\
\hline & & Hystyle & Labrador \\
\hline \multirow[t]{4}{*}{$\overline{32}$} & Leaves & $96.0 \pm 5.9^{\mathrm{NS}}$ & $90.1 \pm 6.1$ \\
\hline & Stem & $23.9 \pm 1.9^{\mathrm{NS}}$ & $23.1 \pm 0.7$ \\
\hline & Flowers & $2.6 \pm 0.2^{\mathrm{NS}}$ & $3.0 \pm 0.1$ \\
\hline & Total & $122.6 \pm 6.9^{\mathrm{NS}}$ & $116.3 \pm 5.9$ \\
\hline \multirow[t]{4}{*}{42} & Leaves & $170.1 \pm 12.2^{\mathrm{Ns}}$ & $152.2 \pm 9.8$ \\
\hline & Stem & $36.1 \pm 2.4^{\mathrm{NS}}$ & $34.5 \pm 2.0$ \\
\hline & Pods & $16.8 \pm 2.1^{*}$ & $12.0 \pm 0.9$ \\
\hline & Total & $223.1 \pm 14.8^{\mathrm{NS}}$ & $198.8 \pm 11.2$ \\
\hline \multirow[t]{4}{*}{50} & Leaves & $220.5 \pm 19.8^{\mathrm{NS}}$ & $190.4 \pm 8.7$ \\
\hline & Stem & $34.1 \pm 3.0^{\mathrm{NS}}$ & $36.7 \pm 2.2$ \\
\hline & Pods & $45.2 \pm 4.0^{*}$ & $31.1 \pm 1.4$ \\
\hline & Total & $299.9 \pm 24.4^{\mathrm{NS}}$ & $258.2 \pm 9.6$ \\
\hline
\end{tabular}

${ }^{2} \mathrm{DAP}=$ days after planting, $\mathrm{n}=7$ at both 32 and 42 DAP and $n=6$ at 50 DAP for each cultivar.

*Indicates that the means are significantly different between 'Hystyle' and 'Labrador' plants using a $t$ test with $P<0.05$; NS $=$ nonsignificant.

The higher transpiration rate by plants in the growth chamber would have resulted in greater water uptake by the roots in relation to Ca uptake, thereby lowering the stem xylem-sap Ca concentration (growth chamber relative to greenhouse plants). Diurnal changes in Ca concentration in the root pressure exudate of poplar (Populus tremula L. $\times$ P. alba L.) have been reported; Ca concentration was highest at night in poplar xylem exudate (Siebrecht et al., 2003). Tanner and Beevers (2001) reported that water transport in the xylem brought about by root pressure and the resulting guttation was sufficient for long-distance Ca transport in sunflower (Helianthus annuus L.). In this study, when plant transpiration was greatly diminished during the night period and exudate was collected from either cultivar, the $\mathrm{Ca}$ concentration was much higher than that of exudate collected from plants either during the day in the greenhouse or from plants in the growth chamber (Table 1). However, the Ca concentration was similar for xylem exudate collected during the night for both 'Hystyle' and 'Labrador'.

Stem xylem-sap Ca concentration in snap bean was also examined by Atkinson et al. (1992), where exudate was collected by placing roots of plants in a pressure chamber. These authors reported $\mathrm{Ca}$ concentrations for the first 50 to $100 \mu \mathrm{L}$ of stem exudate to be $612 \mu \mathrm{g} \cdot \mathrm{mL}^{-1}$ in 'Mihoaca-12A3', $564 \mu \mathrm{g} \cdot \mathrm{mL}^{-1}$ in 'Cacahuate-72', and $180 \mu \mathrm{g} \cdot \mathrm{mL}^{-1}$ in 'Canadian Wonder'. The exudate $\mathrm{Ca}$ concentrations were $\approx 7.5$-fold higher in 'Mihoaca-12A3' and 'Cacahuate-72' and $\approx 2$-fold higher in 'Canadian Wonder' than what we found in 'Hystyle' exudate collected at 32 DAP from plants in the greenhouse. The higher Ca concentration in exudate 
collected from snap bean plants of Atkinson et al. (1992) may be due to the difference in technique used by these authors, or, it merely adds further support to our observation that xylem-sap Ca concentration varies among snap bean cultivars.

WHOLE-PLANT WATER LOSS AND WHOLE-SHOOT CAUPTAKE. There are two possibilities that can explain why 'Labrador' would have a significantly lower xylem-sap Ca concentration than 'Hystyle'. First, if whole-shoot Ca influx is similar between the two cultivars, then a higher whole-plant uptake of water in 'Labrador' would lead to a greater dilution of Ca in the xylem sap of 'Labrador' relative to 'Hystyle'. Alternatively, if whole-plant water uptake is similar between the two cultivars, then higher net influx of $\mathrm{Ca}$ in 'Hystyle' would lead to a higher Ca concentration in the xylem sap of 'Hystyle', relative to 'Labrador'.

To determine whether there was a difference in whole-plant water-use between the two cultivars, plants were placed in a growth chamber under constant environmental conditions in order to maintain steady transpiration rates under equivalent conditions. Although plants of both cultivars were the same size (grams DW), 'Labrador' showed a 35\% higher whole-plant water-use than 'Hystyle' (Table 2). The higher rate of water-use was a result of the larger leaf area (larger transpirational area) of 'Labrador', rather than being due to higher transpiration rates per unit leaf area in this cultivar (data not shown).

Cumulative Ca uptake into the aerial portion of the plant was the same in both cultivars at each developmental stage, indicating that the higher concentration of Ca in the xylem-sap in 'Hystyle' was not due to a higher net influx of $\mathrm{Ca}$ in this cultivar, relative to 'Labrador'. There was a smaller increase in whole-shoot $\mathrm{Ca}$ content in both cultivars from 42 to 50 DAP than from 32 to 42 DAP, which indicated that less $\mathrm{Ca}$ was delivered to the aerial portion of the plant later in development. The reduced Ca uptake and transport by both 'Hystyle' and 'Labrador' late in plant development was mirrored by a reduced xylem-sap Ca concentration in each cultivar from 32 to 50 DAP and demonstrated that net $\mathrm{Ca}$ influx does play a role in the determination of xylem sap $\mathrm{Ca}$ concentration.

Our water-use data support the scenario that 'Labrador' roots take up larger quantities of water than 'Hystyle', such that this dilutes the Ca concentration in the xylem stream of 'Labrador', relative to 'Hystyle'. The similar rates of whole-shoot Ca uptake by these cultivars also support this explanation. Ehleringer et al. (1991) found cultivar variation in water-use efficiency (net mol $\mathrm{CO}_{2}$ fixed per mol $\mathrm{H}_{2} \mathrm{O}$ transpired at the leaf level) and transpiration efficiency (net mol $\mathrm{CO}_{2}$ fixed per mol $\mathrm{H}_{2} \mathrm{O}$ transpired at the canopy level) in a range of common North American bean cultivars. Selecting for increased transpiration efficiency in future snap bean cultivars may result in increased xylem-sap Ca concentration and thereby help to increase pod Ca concentrations.

Grusak et al. (1996a) reported pod Ca concentrations in hydroponically grown 'Hystyle' (3.8 $\left.\mathrm{mg} \cdot \mathrm{g}^{-1} \mathrm{DW}\right)$ and 'Labrador' (2.5 $\mathrm{mg} \cdot \mathrm{g}^{-1} \mathrm{DW}$ ) that were about half the pod Ca concentrations found in greenhouse, soil-grown plants in the present study. Plants of both cultivars grown in hydroponics by Grusak et al. (1996a) were $\approx 2$-fold larger in both plant dry weight and plant Ca content at 50 DAP as compared to our soil-grown plants. Plants in hydroponics were planted at a much higher plant density $\left(20\right.$ plants $\left./ \mathrm{m}^{2}\right)$ than in soil grown plants $\left(6\right.$ plants $\left./ \mathrm{m}^{2}\right)$ in this present study. Grusak et al. (1996a) noted that the pod Ca concentration from hydroponically grown growth chamber plants was lower in both cultivars than when plants were grown in the field. These authors suggested that the lower pod $\mathrm{Ca}$ concentration in the two cultivars was perhaps due to a denser canopy in hydroponically grown plants and thereby a higher humidity microenvironment around pods that would reduce pod transpiration. Grusak and Pomper (1998) showed that raising the humidity levels around pods lowered pod Ca concentrations in both 'Hystyle' and 'Labrador' pods. Humidity levels in the greenhouse were generally lower during the daytime than in the growth chamber (data not shown). The lower humidity in the greenhouse would have helped raise pod $\mathrm{Ca}$ concentrations higher for plants in this environment, relative to pods of hydroponically grown growth chamber plants.

In the present study, we saw a decline in Ca uptake and in xylem-sap Ca concentration from 30 to 50 DAP with soil-grown plants of both 'Hystyle' and 'Labrador'. Similarly, Grusak et al. (1996a) found a decline in net influx of Ca for these two cultivars over this same time period. We found that soil-grown 'Labrador' plants transpired $\left(48 \mathrm{~g} \cdot \mathrm{h}^{-1}\right)$ at a significantly higher rate relative to 'Hystyle' (35 g·h $\left.{ }^{-1}\right)$. In contrast, Grusak et al. (1996a) reported that hydroponically grown 'Hystyle' and 'Labrador' plants both showed similar water-uptake rates per plant for both cultivars of $\approx 29 \mathrm{~g} \cdot \mathrm{h}^{-1}$ from 25 to 50 DAP in a growth chamber. Bean planting density was higher in hydroponically grown plants (20 plants $\left./ \mathrm{m}^{2}\right)$ than in soil-grown plants $\left(6\right.$ plants $\left./ \mathrm{m}^{2}\right)$ in this study. The higher planting density of the hydroponically grown plants may have influenced plant water-use rates. Factors other than whole-plant water-use (e.g., crowding of plants, plant size, stem length, and canopy structure) of the plants grown in hydroponics may have resulted in the observed cultivar differences in pod $\mathrm{Ca}$ concentration.

Cultivar development for enhanced pod Ca ConcentraTION. Plant transpiration efficiency, pod transpiration rates, root uptake of $\mathrm{Ca}$, and $\mathrm{Ca}$ sequestration in the xylem pathway of the stem are important potential regulatory factors that could impact pod $\mathrm{Ca}$ concentration in snap bean. Based on the results of this study, we suggest that if breeders select for cultivars that maintain high xylem-sap Ca concentration (either through higher transpiration efficiency or by increased root $\mathrm{Ca}$ uptake), this could lead to higher pod Ca concentrations in snap bean. Utilizing the amplified fragment length polymorphism (AFLP) marker system and $120 \mathrm{~F}_{2: 3}$ segregating individuals of a snap bean cross, Guzman-Maldonado et al. (2003) found two putative quantitative trait loci significantly associated with $\mathrm{Ca}$ content of the seed. However, the authors did not examine plant water-use or Ca uptake in the progeny.

Further gains in pod $\mathrm{Ca}$ concentration could be achieved if $\mathrm{Ca}$ sequestration in the stem was reduced, such that larger quantities of Ca could be made available for delivery to pods. Both cultivars sequestered almost as much $\mathrm{Ca}$ in stems as in pods (Table 4). Of the total $\mathrm{Ca}$ transported to the aerial portion of the plant by 50 DAP, 'Hystyle' and 'Labrador' partitioned $15 \%$ and $12 \%$, respectively, into pods, whereas 'Hystyle' and 'Labrador' partitioned $11 \%$ and $14 \%$, respectively, into stems. Thus, significant gains in pod $\mathrm{Ca}$ concentration could be achieved in both cultivars if $\mathrm{Ca}$ sequestration in the stem pathway was reduced.

In conclusion, using the snap bean cultivars 'Hystyle' and 'Labrador' that exhibit high and low pod Ca levels respectively, we demonstrated that differences in whole-plant water use impacted xylem-sap $\mathrm{Ca}$ concentration, and this further impacted pod $\mathrm{Ca}$ concentration. It is worth noting that the more water-use efficient cultivar had more $\mathrm{Ca}$-dense pods. Selection for water use efficiency in bean, therefore, would be not only advantageous to the farmer and the environment, but would benefit the consumer as well. 


\section{Literature Cited}

Atkinson, C.J., L.P. Ruiz, and T.A. Mansfield. 1992. Calcium in xylem sap and the regulation of its delivery to the shoot. J. Expt. Bot. 43:1315-1324.

Bell, C.W. and O. Biddulph. 1963. Translocation of calcium. Exchange versus mass flow. Plant Physiol. 38:610-614.

Biddulph, O., R. Cory, and S. Biddulph. 1959. Translocation of calcium in the bean plant. Plant Physiol. 34:512-519.

Biddulph, O., F.S. Nakayama, and R. Cory. 1961. Transpiration stream and ascension of calcium. Plant Physiol. 36:429-436.

Bruce, W.R. 1987. Recent hypotheses for the origin of colon cancer. Cancer Res. 47:4237-4242.

Ehlreringer, J.R., S. Klassin, C. Clayton, D. Sherrill, M. Fuller-Holbrook, Q. Fu, and T.A. Cooper. 1991. Carbon isotope discrimination and transpiration efficiency in common bean. Crop Sci. 31:1611-1615.

Ehret, D.L. and L.C. Ho. 1986. Translocation of calcium in relation to tomato fruit growth. Ann. Bot. 58:679-688.

Grusak, M.A. 1994. Iron transport to developing ovules of Pisum sativum. I. Seed import characteristics and phloem iron-loading capacity of source regions. Plant Physiol. 104:649-655.

Grusak, M.A., S. Pezeshgi, K.O. O’Brien, and S.A. Abrams. 1996b. Intrinsic ${ }^{42} \mathrm{Ca}-$ labelling of green bean pods for use in human bioavailability studies. J. Sci. Food Agr. 70:11-15.

Grusak, M.A., B.W. Stephens, and D.J. Merhaut. 1996a. Influence of whole-plant net calcium influx and partitioning on calcium concentration in snap bean pods. J. Amer. Soc. Hort. Sci. 121:656-659.

Grusak, M.A. and K.W. Pomper. 1998. Influence of pod stomatal density and pod transpiration on the calcium concentration of snap bean pods. J. Amer. Soc. Hort. Sci. 124:194-198.

Guzman-Maldonado, S.H., O. Martinez, J.A. Acosta-Gallegos, F. Guevara-Lara, and O. Paredes-Lopez. 2003. Putative quantitative trait loci for physical and chemical components of common bean. Crop Sci. 43:1029-1035.

Hall, R. 1991. Compendium of bean diseases. American Phytopathol. Soc. Press, St. Paul, Minn.

Heaney, R.P., C.M. Weaver, and R.R. Recker. 1988. Calcium absorbability from spinach. Amer. J. Clinical Nutr. 47:707-709.

Hose, E., D.T. Clarkson, E. Steudle, L. Scheiber, and W. Hartung. 2001. The exodermis: a variable apoplastic barrier. J. Expt. Bot. $52: 2245-2264$.

Institute of Medicine. 1997. Dietary reference intakes for calcium, phosphorus, magnesium, vitamin D, and fluoride. Standing Committee on the Scientific Evaluation of Dietary Reference Intakes. Food and Nutrition Board. Natl. Academy Press, Washington, D.C.

Johnston Jr., C.C., J.Z. Miller, C.W. Slemenda, T.K. Reister, S. Hui, J.C. Christian, and M. Peacock. 1992. Calcium supplementation and increases in bone mineral density in children. New England J. Med. 327:82-87.

Linder, M.C. 1991. Nutritional biochemistry and metabolism: With clinical applications. 2nd ed. Elsevier, New York.

Miglioranza,E., P.Barak, K.Kemiecik, and J. Nienhuis. 1997. Comparison of soil and genotypic effects on calcium concentration of snap bean pods. HortScience 32:68-70.

Mix, G.P. and H. Marschner. 1976. Einflub exogener und endogener Faktoren auf den Calciumgehalt von Paprika- und Bohnenfrüchten (Effect of external and internal factors on the calcium content of paprika [pepper] and bean fruits). Z. Pflanz. 5:551-563.

Nonami, H. and J.S. Boyer. 1987. Origin of growth-induced water potential. Solute concentration is low in apoplast of enlarging tissues. Plant Physiol. 83:596-601.

Pao, E.M., K.H. Fleming, P.M. Guenther, and S.J. Mickle. 1982. Foods commonly eaten by individuals: Amount per day and per eating occasion. Consumer Nutr. Ctr., Human Nutr. Info. Serv., U.S. Dept. Agr. Home Econ. Res. Rpt. No. 44.

Penninton, J. and B. Young. 1991. Total diet study nutritional elements, 1982-1989. J. Amer. Dietetic Assn. 91:179-183.

Quintana, J.M., H.C. Harrison, J. Nienhuis, J.P. Palta, and M.A. Grusak. 1996. Variation for calcium concentration among sixty $\mathrm{S} 1$ families and four cultivars of snap bean (Phaseolus vulgaris). J. Amer. Soc. Hort. Sci. 121:789-793.

Raven, J.A. 1977. $\mathrm{H}^{+}$and $\mathrm{Ca}^{2+}$ in phloem and symplast: Relation of relative immobility of the ions to the cytoplasmic nature of the transport paths. New Phytol. 79:465-480.

Siebrecht, S., K. Herdel, U. Schurr, and R. Tischner. 2003. Nutrient translocation in the xylem of poplar-diurnal variations and spatial distribution along the shoot axis. Planta 217:783-793.

Tanner, W. and H. Beevers. 2001. Transpiration, a prerequisite for long-distance transport of minerals in plants? Proc. Natl. Acad. Sci. 98:9443-9447.

White, P.J. 2001. The pathways of calcium movement to the xylem. J. Expt. Bot. 52:891-899.

Zindler-Frank, E. 1995. Calcium, calcium oxalate crystals, and leaf differentiation in the common bean. Bot. Acta 108:144-148. 